Europe's Journal of Psychology 2/2009, pp. 41-63

www.ejop.org

\title{
Conflict Resolution Strategies and Organisational Citizenship Behaviour: The Moderating Role of Trait Emotional Intelligence
}

Samuel O. Salami

University of lbadan

\begin{abstract}
This study investigated the relationship between conflict resolution strategies and organisational citizenship behaviour (OCB) and the moderating role of trait emotional intelligence (El). Participants were 320 public servants (male $=180$, female $=140$ ) randomly selected from five states in Southwestern Nigeria. Measures of trait $\mathrm{El}, \mathrm{OCB}$, and conflict resolution strategies were administered to the respondents. Multiple regression was used to analyse the data collected. The results indicate that forcing and withdrawing strategies negatively and significantly predicted OCB. Confronting, compromising and smoothing strategies significantly predicted OCB. Trait El moderated the relationship between $\mathrm{OCB}$ and forcing and withdrawing strategies. It was recommended that counsellors and psychologists should develop programmes to foster emotional intelligence and conflict resolution for both subordinates and superiors in work organisations.
\end{abstract}

Keywords: Conflict resolution, organisational citizenship behaviour, trait El, work attitudes, work-related behaviour.

Introduction

Over the years, several studies have linked resolution of conflicts in organisational settings with work performance or work indicators (attitudes) (Alper, Law, \& Tjosvold, 2000; Meyer, 2004; Ogungbamila, 2006). The federal government's implementation of the monetization policy and organisational changes/restructuring engendered a lot of interpersonal conflict between the workers and the management in several organisations in Nigeria because the workers' unions were not given fair hearing in their organisations (Adebayo, 2006). However, the attitudes of public service workers 
in Nigeria following a conflict resolution process have not been adequately investigated by previous researchers (Adebayo, 2006). Conflict resolution strategies adopted in resolving conflicts between workers and management may influence the workers' attitude regarding work and the organisation. Workers who felt they were not given fair hearing in the resolution of a conflict may develop negative attitude to work or their organisation such as low organisational citizenship behaviour (OCB) (Moorman, 1991; Podsakoff, Mackenzie, Paine \& Bachrach, 2000).

This study was focused on the workers in the public service in Nigeria because many of the public enterprises have undergone organisational changes and restructuring in order to improve operational efficiency and competitiveness. These organisational changes and restructuring have resulted in the retrenchment of many workers in the public service (Adebayo, 2006). The retrenchment had grave psychological consequences for the laid-off workers and the survivors of layoffs who remained on the job. The workers union's strikes negotiations and protests did stop the government from the retrenchment.

The management of most government ministries and firms used a combination of conflict resolution strategies to resolve the conflicts that arose. The consequences of management's use of uncooperative conflict resolution strategies such as forcing and withdrawing strategies for the survivors of the layoffs have been job insecurity and negative attitude to work and the organisation. The survivors of the layoffs had been reported to have experienced anxiety about losing their jobs, lower morale, decreased loyalty, distrust, negative attitude to work and organisation, reduction in productivity, creativity, organisational commitment, job satisfaction and organisational citizenship behaviour (OCB) (Adebayo, 2006; Moorman, 1991; Podsakoff et al., 2000; Sverke, Hellgren \& Naswell, 2006). The survivors of layoffs have perceived their managements and superiors as perpetuating organisational injustice. The more the employees perceived organisational injustice and unfairness as arising from their management's use of uncooperative and negative conflict resolution strategies in the work place, the more they reciprocated by exhibiting more negative attitudes to work and the organisation such as reduced organisational commitment, trust, loyalty and withholding OCB. All these have subsequently led to further conflicts between the management and the workers (Adebayo, 2006).

Thus, there is need to examine the effects of the different conflict resolution strategies on the work attitudes of the workers. This is because a worker who has experienced work-place frustration or suffered organisational injustice arising from 
the way management-worker conflicts were resolved may engage in counterproductive work activities such as character assassination, spreading negative rumours, sabotaging, turnover, (Alper, Law \& Tjosvold,2000; Meyer,2004;Ogungbamila, 2006) and withholding organisational citizenship behaviour (OCB) (Alotaibi, 2001; Giap, Hackermeier, Jiao \& Wagdarikar, 2005; Moorman, 1991; Podsakoff et al. 2000; Zellars Tepper \& Duffy, 2002).

For a worker who has experienced work-place frustration or organisational injustice arising from the conflict resolution strategies adopted by management in resolving the management worker conflict, being emotionally competent or intelligent is not only important but a necessary ingredient for positive attitude to work and organisation and a successful career in the organisation. According to Meyer \& Salovey (1997), Emotional intelligence is the ability to perceive accurately, appraise and express emotion; ability to access and or generate feeling that facilitate thought, understand emotion and regulate one's and others' emotions.

Abrahim (1999) and Carmeli (2003) were of the view that traits El may enhance helping behaviour and other citizenship behaviours because it enables employees to comprehend their superiors' and co-workers' feelings and to respond better than employees with low trait El. Mikolajczak, Petrides, Luminet and Coumans (2007) found that high trait El people display less of an increase in distress than their low trait El peers in response to various adverse events or conditions in the workplace. Mikolajczak, Nelis, Hansenne, and Quoidbad (2008) reported that trait El helps in moderating the effects of unfair treatment or organisational injustice on individuals' OCB on the ground that individuals with high trait El would have the ability to appraise the situation, their resources, process the emotional information arising from organisational injustice or unfair treatment and select adaptive coping strategies rather than use maladaptive coping strategies to deal with the negative events. Through this process, unfairly treated individuals with high trait El will likely develop high OCB. It is thus expected that trait El will moderate the relationship between conflict resolution strategies and $\mathrm{OCB}$.

The purpose of this study was to examine how much of the organisational citizenship behaviour could be predicted by the five conflict resolution strategies (forcing, smoothing, compromising, confronting and withdrawing) proposed by Howart and London (1980) and the moderating role of trait El in the prediction. 
Conflict Resolution

Conflict is a social problem in which two or more persons, families, parties, communities, or districts are in disagreement with each other (Dzurgba, 2006). Interpersonal conflict is a disagreement between two or more persons. Organisational conflict is a disagreement between or within groups in an organisation. The groups may be workers, workers' unions or management. Organisational conflict is common in the workplace because people always have divergent views on various issues, interests, ideologies, goals, and aspirations (Deutsch, 1990). Some negative consequences of conflict can undermine an organisation's efforts. However, handled correctly, conflict can benefit individuals and organisations by producing stronger, more resilient working relationship, improving creative output and generating innovative solutions (Omoluabi, 2001).

Conflict resolution is a relational approach to handling conflicts. It is a process in which interpersonal communication is used to get the parties to a conflict to reach an amicable and satisfactory point of agreement (Albert, 2005; Omoluabi, 2001). The five conflict resolution strategies: confronting/collaborating, withdrawing/ avoiding, forcing/competing, smoothing, and compromising, adopted by conflicting parties during conflict resolution are identified depending on the level of the win/lose orientation of the parties involved (Meyer, 2004; Ogungbamila, 2006).

McShane \& Von Glinow (2001) introduced the dimension of assertivenesscooperativeness and win-win and win-loss orientation along the continuum in describing each of the five conflicts resolution strategies. For example, persons using confronting/collaborating, smoothing and compromising strategies are said to exhibit high cooperativeness and low assertiveness behaviours. Also they are said to adopt more win-win orientation and less win-loss orientation attitudes. Persons using withdrawing/avoiding and forcing/competing strategies are considered to exhibit high assertiveness and low cooperativeness behaviours. They are also considered to adopt more win-loss orientation than win-win orientation attitudes.

The confronting/collaborating strategy is one in which one party shares information and clarifies issues on the point of conflict with the other party so as to reach a solution acceptable to both parties. Collaborating strategies ranks high on both assertiveness and cooperativeness, supporting a win-win orientation. They may engender positive work behaviour and attitudes of the parties in conflict (McShane \& Von Glinow, 2001). The compromising strategy is a give-and-take method of resolving conflict. Each party gives up something that the other party wants. It rates 
low on assertiveness and high on cooperativeness. This strategy may result in positive work behaviour and attitudes. The forcing or competitive strategy is one in which one party adopts a competing strategy to force the other party to accept a particular position. The forcing strategy rates very high on assertiveness but is low in its cooperation with others. This strategy reveals a win-lose orientation and may result in negative work behaviour of the party that has to lose.

Smoothing strategy is one that involves avoiding conflict. The smoothing strategy rates low on assertiveness and high on cooperativeness, de-emphasizes differences and highlights points common to both parties. This strategy may also result in positive work behaviour and attitudes. Withdrawal strategy involves the tendency of a party to a conflict to refrain from and ignore the conflict altogether rather than trying to directly resolve it. This strategy has the tendency to engender counterproductive work behaviour (Alper et al. 2000; Meyer, 2004; Ogungbamila, 2006; Omoluabi, 2001).

Organisational Citizenship Behaviours (OCB)

Organisational Citizenship Behaviours (OCB) are those voluntary, above the call of duty behaviours that do not only contribute to company success but are discretionary and not directly or explicitly recognized by formal reward systems (Organ, 1988; McShane \& Von Glinow, 2001). Organ (1988) identified five categories of OCB: altruism - helping of an individual co-worker on a task; courtesy - alerting others in the organisation about changes that may affect their work; conscientious carrying out one's duties beyond the minimum requirements; sportsmanship refraining from complaining about trivial matters; and civic virtue - participating in the governance of the organisation. Podsakoff and Mackenzie (1994) modified the categorizations, merged altruism and courtesy and termed it "helping". Based on Organ's (1988) five-dimension taxonomy, Williams and Anderson (1991) proposed a two-dimensional conceptualization of OCB: OCB-1 (behaviours directed toward individuals compromising altruism and courtesy) and OCB-O (behaviours directed toward the organisation: comprising the remaining three-dimension in Organ's (1988) conceptualization). Decktop, Mangel and Cirka (1999) have utilized a unidimension or overall $\mathrm{OCB}$ measure in their research. A most recent meta-analysis conducted by Hoffman, Blair, Meriac \& Woehr, (2007) suggested that the current operationalization of OCB are best viewed as indictors of a general OCB factor, there is likely little to be gained through the used of separate dimensional measures as opposed to an overall composite measure. A similar conclusion was reached by a previous metaanalysis (LePine, Erez, \& Johnson, 2002). 
Based on the recommendations from the literature on organisational citizenship behaviours, I used Organ's (1988) five categories of OCB as modified by Podsakoff \& McKenzie (1994) consisting of helping behaviour (altruism and courtesy merged), sportsmanship and civic virtue.

When there is a general sense of procedural fairness in the organisation, people are more likely to go out of their way to help others, be courteous, and go an extra mile for customers and colleagues (Organ, 1988). Procedural fairness means the extent to which organisational decisions are made equitably and with employee input. It is also the extent to which employees are fairly rewarded given their level or training, tenure, responsibility or workload (Moorman, 1991). Similarly, when conflicts are resolved in the organisation and the parties involved in the conflict are fairly treated, then there could be said to be procedural fairness. Procedural fairness occurs when the employees feel that there are policies and rules in place that ensure fair treatment (Moorman, 1991). When managers or superiors use unfair procedures employee's sense of trust is affected. This can in turn have negative consequences on organisational citizenship behaviour (Miles, Borman, Spector \& Fox, 2002; Podsakoff et al. ,2000).

The consequences of organisational citizenship behaviour have been well documented in the literature. For instance, several researchers have found that $\mathrm{OCB}$ resulted in organisational effectiveness, efficiency and group performance (Podsakoff et al., 1997) and unit performance (Podsakoff \& MacKenzie, 1994). Other consequences of OCB include higher salary and promotion, higher organisational commitment (Allen, 2006), lower turnover and intention to leave the organisation and reduced potential for burnout in workers (Garma, Bove \& Bratton, 2008).

\section{Conflict resolution strategies and $\mathrm{OCB}$}

Empirical evidence generally indicated that studies on the antecedents of OCB, particularly conflict resolution styles, are scarce and not well established (Podsakoff \& Mackenzie, 1994; Podsakoff, Ahearne \& Mackenzie, 1997). Few studies that are related to the constructs investigated in this study are reported here. For example, conflict resolution strategies were found to be significantly related to organisational citizenship behaviour (Alotaibi, 2001; Giap, Hackermeier, Jiao \& Wagdarikar, 2005).

Ogungbamila (2006) found that the forcing strategy had a direct significant relationship with work frustration while confronting, withdrawing, smoothing and compromising strategies did not. Furthermore, Montoro-Rodriguez and Small (2006) 
reported that nurses' job satisfaction, psychological morale and occupational stress were influenced by conflict resolution strategies. Similarly, some studies have linked conflict resolution strategies with work performance or work indicators (Alper, Law \& Tjosvold, 2000; Meyer, 2004).

Subordinates who are unfairly treated by their supervisors' use of forcing and withdrawing conflict resolution strategies are likely to withhold their OCB. Based on the above assertions, the following hypotheses were generated:

Hypothesis 1: Forcing conflict resolution strategy will predict organisational citizenship behaviour (OCB).

Hypothesis 2: Withdrawing conflict resolution strategy will predict OCB.

Subordinates whose supervisors use confronting strategy will likely reciprocate this supportive leadership behaviour by performing more OCBs.

Hypothesis 3: Confronting conflict resolution strategy will predict OCB.

When subordinates perceive that their supervisors used compromising strategy they are likely to demonstrate more OCBs.

Hypothesis 4: Compromising conflict resolution strategy will predict OCB.

Subordinates whose superiors use smoothing strategy in resolving conflict are likely to enact more OCBs

Hypothesis 5: Smoothing conflict resolution strategy will predict OCB.

Trait El and OCB

Emotional intelligence (EI) is a concept proposed to account for the variability in the individual's ability and propensity to regulate their emotion. El aims to provide a scientific framework for the idea that individuals differ in the extent to which they attend to, process, and utilize affect-laden information of an intrapersonal (e.g. regulating one's own emotions) or interpersonal (e.g. regulating others' emotion) nature (Petrides \& Furnham, 2003). There are two types of emotional intelligence (EI): Trait El and Ability El, which can be distinguished on the measurement method used to operationalize the construct (Furnham \& Petrides, 2003).

On the one hand, trait El (emotional self-efficacy) is operationalised through selfreport questionnaire (Furnham \& Petrides, 2003). It is a constellation of emotional 
related self-perceived abilities and dispositions located at the lower levels of personality hierarchies (Petrides \& Furnham, 2001). Trait El is the ability to perceive accurately, appraise, and express emotion; the ability to access and/or generate feelings when they facilitate thought; the ability to understand emotion and emotional knowledge; and the ability to regulate emotions to promote emotional and intellectual growth (Mayer \& Salovey, 1997).

On the other hand, ability El (or cognitive-emotional ability) is operationalised through maximum performance tests, that is, tests comprising items that may be answered correctly or incorrectly (Mayer \& Salovey, 1997). Ability El is considerably complicated by the fact that emotional experiences are inherently subjective (Furnham \& Petrides, 2003) and are not amenable to objective scoring criteria. Ability El is defined as the ability to perceive accurately, appraise, and express emotion; the ability to access and/or generate feelings when they facilitate thought; the ability to understand emotion and emotional knowledge; and the ability to regulate emotions to promote emotional and intellectual growth (Mayer \& Salovey, 1997).

At this point, there is a need to point out the distinction between trait El and ability El. The former encompasses behavioural dispositions. It encompasses individuals' perception, processing, regulation and utilization of emotional information (Mikolajczak, Nelis Hansenne \& Quoidbach, 2008). Individuals with high trait El scores believe they are in touch with their emotions and that they can regulate them in a way that promotes well-being. These individuals should enjoy high level of happiness (Furnham \& Petrides, 2003) and self-perceived abilities. Trait El is measured through self-report, whereas the latter concerns actual abilities and ought to be measured with maximum performance rather than self-report tests (Petrides \& Furnham, 2001). Because trait El relates to behavioural tendencies and self-perceived abilities, its investigation should be conducted primarily within a personality framework. In contrast, ability El should be studied primarily with respect to psychometric intelligence. Trait El is assessed by means of self-report measures, which have great overlap with other established measures of personality, depression and well-being (Davies, Stankov \& Roberts, 1998). Ability El measures assess actual abilities.

It is easier to administer self-report measures of trait El with subjects and it takes less time to administer them. However, ability El measures are based on maximum performance tests that require the researchers' responses. Laboratory experiments may require participants to complete lengthy and complicated tasks (Geher, Warner \& Brown, 2001). 
Trait El may enhance helping behaviour and other citizenship behaviours because it enables employees to comprehend their co-workers' feelings and to respond better than employees with low trait El (Abraham, 1999). Indeed, individual with high trait El may engage in helping behaviour because being in a good mood is reinforcing and displaying helping behaviour is rewarding (Carmeli, 2003). People in good moods are more socially interactive. Employees who have positive emotional reactions to their jobs are more likely to be engaged in helpful behaviour. Thus, the following hypothesis is suggested:

Hypothesis 6: Trait El will predict OCB.

Individuals with high trait El are likely to have the ability to appraise the situation and their resources, process the emotional information, and choose an adaptive coping strategy by assertively seeking fair treatment from their employers rather than use maladaptive coping strategies that may result in withdrawal of OCBs.

Moderating Effects of Trait El

The literature suggests that the negative effects of conflict resolution strategies forcing and withdrawing strategies on work attitudes may be moderated by several variables including trait El (see for example, Carmeli 2003; Martins, Eddleston \& Veiga, 2002; Mikolajczak, Luminet, Leroy, \& Roy, 2007). In this study, trait El is expected to moderate the relationship between conflict resolution strategies and OCB. Unfair treatment arising from superior's use of forcing or withdrawal/avoidance or uncooperative conflict resolution strategies may have some negative consequences on the extent to which an employee will exhibit OCB. For example, Mikolajczak, Petrides, Luminet and Coumans (2007) have repeatedly found that high trait El people display less of an increase in distress than their low trait El peers in response to various adverse events or conditions. In applied settings, nurses with high trait El scores reported lower levels of burnout and somatic complaints than nurses with lower scores (Mikolajczak, Menil \& Luminet, 2007; Mikolajczak, Petrides, Luminet \& Coumans, 2007; Mikolajczak, Roy, Luminet, Fillee \& de Timary, 2007).

Certain processes might have accounted for the adaptive effects primarily appraisals, automatic processing of emotional information and coping strategies (Mikolajczak, Nelis, Hansenne \& Quoidbach, 2008). There is evidence that trait El influences the appraisal of both the situation and one's resources to face it, and that these appraisals mediate the effect of trait El on the emotional response to the situation (Mikolajczak, Menil \& Luminet, 2007). There is also evidence that trait El 
might influence the choice of coping strategies, that is, the specific behavioural and psychological strategies that people implement in order to deal with negative events. Petrides, Perez-Gonzalez \& Furnham (2007) have shown that trait El is positively associated with the use of adaptive coping strategies (e.g. problemfocused coping) and negatively associated with the use of maladaptive coping strategies (e.g. avoidance).

However, individuals with high trait El scores are likely to have the ability to appraise both the situation and their resources, process the emotional information arising from the unfair treatment or organisational injustice and select adaptive coping strategies (e.g. problem-focused coping) by assertively seeking fair treatment from their employers rather than using maladaptive coping strategies (e.g. avoidance and violence) in order to deal with negative events (Mikolajczak et al. , 2008). Through this process, unfairly treated individuals with high trait El will likely develop high OCB. Therefore, it is expected that trait El will interact with conflict resolution strategies and thereby help to enhance OCB of the workers. There is scarce literature on moderating role on trait El on the relationship between conflict resolution strategies and OCB. For this reason, we therefore formulate this hypothesis:

Hypothesis 7: Trait El moderates the relationship between each of the conflict resolution strategies (forcing, withdrawing, confronting, compromising and smoothing) and OCB. The interaction between trait El and each of the conflict resolution strategies (forcing, withdrawing, confronting, compromising and smoothing) will predict OCB.

Method

Participants

Three hundred and twenty participants responded to the survey. One hundred and eighty (56.25\%) were male and 140 (43.75\%) female. Their ages ranged from 25 to 55 years with a mean age of 32.50 (S.D. $=9.20$ ). The educational qualifications of the participants ranged from primary school certificate to University degree. Eighteen (5.6\%) had primary school certificate, 84 (26.25\%) had secondary school certificate, 104 (32.5\%) had Nigeria Certificate in Education (NCE)/Ordinary National Diploma (OND), 79 (24.68\%) had B.Sc., B.A., B.Ed./HND and 35 (10.93\%) had master's degrees. The participants' job status varied from low (248), middle (40) to high (32). Employees from low, middle and high level of organisation were involved in the study because they were survivors of mass retrenchment exercise and had experienced unfair 
treatment arising from their superior's use of conflict of resolution strategies supported by an assertive and uncooperative orientation.

Instruments

Conflict Resolution Strategies Scale (CRSS) (Howart \& London, 1980) was used to measure the perception of the participants to their superior's typical behaviour when resolving conflicts in the workplace on a 5 -point scale ( 1 = never to $5=$ always). The CRSS is a 25-item inventory with 5 subscales consisting of confronting withdrawing, forcing, smoothing, and compromising respectively. Howart \& London (1980) obtained the following Cronbach's alpha values for CRSS subscales: 0.84 (confronting), 0.66 (withdrawing) 0.84 (forcing), 0.73 (smoothing) and 0.64 (compromising) respectively. For this study, the Cronbach's alpha reliability coefficients obtained for the CRSS subscales were 0.80 (confronting), 0.72 (withdrawing), .82 (forcing), .72 (smoothing) and .70 (compromising) respectively. Sample items for each subscale of CRSS are: "He/She brings the problems clearly into the open and carries it out to resolution" (confronting); "He/She gives in a little to get a little" (compromising); "He/She imposes his/her solution" (forcing); "He/She plays down our differences" (smoothing); and "He/She tries not to get involved" (withdrawing). The higher the scores the higher the extent to which the superior usually used the style to resolve conflict. The CRSS has been used with success by Ogungbamila (2006) with Nigerian samples.

Organisational citizenship behaviour (OCB) was measured by means of the OCB measure by Podsakoff and Mackenzie (1994). It consisted of 3 sections: helping behaviour (7 items), sportsmanship (3 items) and civic virtue (3 items). The workers' ratings of their superiors' citizenship behaviours were obtained on a 5-point Likert Type scale ranging from 1 = strongly disagree to $5=$ strongly agree. For this study, the Cronbach's alpha reliability coefficients for helping $=.95$, civic virtue $=.96$, and sportsmanship $=.88$ while that for the whole OCB scale was 0.93. Sample item for each subscale of OCB were: Help each other if someone falls behind in his/her work (Helping). Provide constructive suggestions about how colleagues can improve their effectiveness (Civic virtue). Always focus on what is wrong with our situation, rather than the positive side (Sportsmanship, reverse scored). The OCB measure was used as a undimensional scale.

Trait El was measured by means of a 16-item emotional scale developed by Wong and Long (2002) (WLEIS) and based on the model developed by Davies, Stankov and Roberts (1998) and Mayer and Salovey (1997). The response format for WLEIS 
was a 5 -point Likert-type scale ( 1 = strongly disagree to $5=$ Strongly agree). The WLEIS has 4 subscales with 4 items each: Self-emotions appraisal (4 items, a=0.90), Use of emotions ( 4 items, $a=0.79$ ), Regulation of emotions ( 4 items, $a=0.89$ ), Others' emotions appraisal (4 items, $a=0.93$ ). Sample item for each subscale of WLEIS are: "I have good understanding of my own emotions" (Self-Emotions Appraisal, SEA); "I always know my friends' emotions from their behaviour" (Other's Emotions Appraisal, OEA), "I would always encourage myself to try my best" (Use of Emotion, UOE), "I am quite capable of controlling my own emotions" (ROE). WLElS could be used as a multidimensional or unidimensional scale. A Cronbach alpha reliability coefficient of $a=0.87$ was obtained for WLEIS when used as a unidimensional scale in this study.

Procedure

Participants were randomly selected across all ministries in five states in southwestern Nigeria through the help of some assigned personnel. The three questionnaires were distributed to the participants in their work places. The purpose of the study - which was given as an academic research exercise designed to know the participants' ratings of the conflict resolution strategies used by their superiors in their organisations and their perceived OCB - was explained to the participants. A section of the questionnaire had background information on the participants' age, sex, education, job status, and tenure with the organisation. The questionnaires were completed anonymously by the participants in their offices, units or departments and were collected by the assigned personnel for subsequent analysis by the researcher. Data were collected from 400 respondents, however, 320 questionnaires were analyzed giving a response rate of $80.0 \%$. The others were either not completely filled in or the participants' tenure in the organisation was less than 6 months.

Data Analysis

Control variables were age, sex, education, tenure and job status and were treated as covariates to reduce error variance (Aiken \& West, 1991). Age, sex, education, job status and tenure were treated as control variables because previous researchers have proved that they exert some influence on OCB (Salami, 2007, 2008; Zellars, Tepper \& Duffy, 2002). The independent variables were the conflict resolution strategies - confronting, compromising, forcing, smoothing, and withdrawing. The moderator variable was trait El while the dependent variable was OCB. Hierarchical multiple regression analysis was used to analyze the data in order to examine the prediction of OCB from the five conflict resolution strategies. In the first step the control variables were entered. At the second step conflict resolution strategies and 
trait El were entered. Step 3 tested the interaction effects between conflict resolution strategies and trait El.

Results

Means, standard deviations, intercorrelations and reliabilities (Cronbach's alpha) for each scale are presented in Table 1. All scale reliabilities ranged from .64 to .93. Results on Table 1 reveal that all the control variables had non-significant relationships with OCB. This results could be attributed to the fact that all the participants were survivors of layoffs who had witnessed their managements' use of certain negative conflict resolution strategies in handling conflicts in their organisation which had made them to develop negative attitude to work and organisation and reduced their OCB regardless of their age, sex, education, tenure, and job status. Significant positive relationships were obtained between $O C B$ and Trait El $\left(r_{(318)}=.36, P<0.05\right)$, confronting $\left(r_{(318)}=.33 P<.05\right)$, smoothing $\left(r_{(318)}=.35, P<.05\right)$, and compromising strategies $\left(r_{(318)}=.28, P<.05\right)$. However, OCB had significant negative relationships with withdrawing $\left(r_{(318)}=-.20, P<.05\right)$, and forcing strategies $\left(r_{(318)}=-.24, P<.05\right)$.

Table 1: Means, S.D. and Zero-order correlations of all variables in the study $(\mathrm{N}=320)$

\begin{tabular}{|c|c|c|c|c|c|c|c|c|c|c|c|c|c|}
\hline & Variable & 1 & 2 & 3 & 4 & 5 & 6 & 7 & 8 & 9 & 10 & 11 & 12 \\
\hline 1 & OCB & $(.93)$ & & & & & & & & & & & \\
\hline 2 & Trait El & $.36^{*}$ & $(.87)$ & & & & & & & & & & \\
\hline 3 & Confronting & $.33^{*}$ & $.20^{*}$ & $(.84)$ & & & & & & & & & \\
\hline 4 & Withdrawing & $-.20^{*}$ & .12 & -.09 & $(.66)$ & & & & & & & & \\
\hline 5 & Forcing & $-.24^{*}$ & .12 & -.16 & .16 & $(.84)$ & & & & & & & \\
\hline 6 & Smoothing & $.35^{*}$ & $.19^{*}$ & $.26^{*}$ & .17 & .18 & $(.73)$ & & & & & & \\
\hline 7 & Compromising & $.28^{*}$ & .21 & $.30^{*}$ & .17 & .18 & $.20^{*}$ & $(.64)$ & & & & & \\
\hline 8 & Age & .07 & .03 & .08 & .18 & .15 & .07 & .15 & & & & & \\
\hline 9 & Sex & .02 & .05 & .12 & .07 & .18 & .13 & .02 & .10 & & & & \\
\hline 10 & Tenure & .12 & .15 & .08 & .14 & .15 & .17 & .05 & $.21^{*}$ & .07 & & & \\
\hline 11 & Education & .14 & .18 & .05 & .13 & .12 & .06 & .12 & $.20^{*}$ & .03 & .16 & & \\
\hline 12 & Job Status & .03 & .11 & .02 & .12 & .08 & .05 & .18 & $.19^{*}$ & .12 & $.22^{*}$ & $.23^{*}$ & \\
\hline & Means & 48.24 & 50.32 & 17.40 & 12.30 & 0.41 & 18.20 & 18.60 & 32.50 & 1.50 & 8.5 & 2.60 & 1.60 \\
\hline & S.D. & 3.40 & 2.70 & 5.00 & 3.45 & 4.20 & 1.80 & 3.42 & 9.20 & 0.50 & 7.50 & 3.30 & 6.50 \\
\hline
\end{tabular}

Consistent with the hypothesized model, results of the hierarchical multiple regression analysis showed that the overall model was significant $\left(R^{2}=.48, \Delta R^{2}=.13, F(16,303)=8.75\right.$, $P<.05)$. 
Table 2: Hierarchical Regression Analysis for the prediction of OCB from conflict resolution strategy with trait El as moderator $(n=320)$

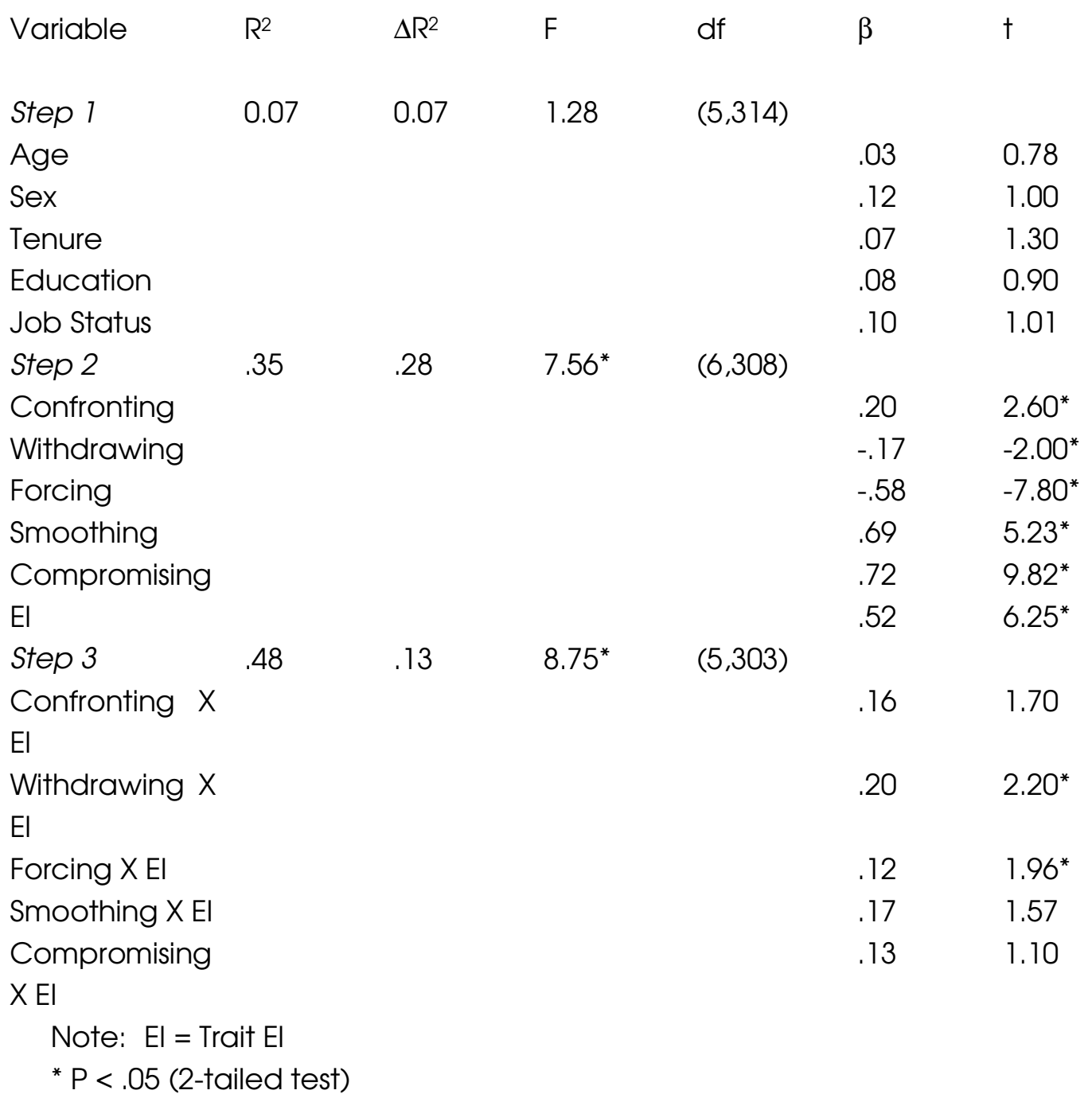

In step 1, control variables (age, sex, education, job status and tenure with the organisation) entered did not make significant contribution (7.0\%) to the variance in

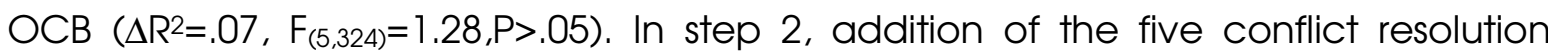
strategies and trait El made significant contribution (28\%) to the variance of OCB $\left(\Delta \mathrm{R}^{2}=.28, \mathrm{~F}_{(6,308)}=7.56, \mathrm{p}<.05\right)$.

Forcing and withdrawing conflict resolution strategies negatively and significantly predicted OCB ( $\beta=-.58, t=-7.80, p<.05$ and $\beta=-.17, \dagger=-2.00, P<.05$ respectively), thus Hypotheses 1 and 2 were supported. These mean that the more the superiors used forcing and withdrawing conflict resolution strategies the less the subordinates exhibited OCB. Supporting Hypotheses 3, 4 and 5, results showed that confronting $(\beta=.20, \dagger=2.60, P<.05)$, compromising $(\beta=.72, \dagger=9.82, P<.05)$ and smoothing $(\beta=.69, \dagger$ 
$=5.23, P<.05)$, conflict resolution strategies significantly predicted OCB. Support was also found for Hypothesis 6. Subordinates with high trait El developed higher OCB ( $\beta$ $=.52, \mathrm{\dagger}=6.25, \mathrm{P}<.05$ ).

In step 3, the inclusion of the interaction terms between conflict resolution strategies and trait El accounted for an additional 13.0 percent of the variance in $\mathrm{OCB}\left(\mathrm{F}_{(8,303)}\right.$ $=8.75, \mathrm{P}<.05)$. That the predictive value of $\mathrm{El}$ and conflict resolution strategies taken alone are higher than the predictive value of the interaction could be interpreted to mean that El and conflict resolution strategies made significant contribution to the prediction of OCB whereas only two of the conflict resolution strategies interacted with El significantly to make a moderate contribution to the prediction of OCB. Results further showed that there were significant positive interactions between withdrawing strategy and trait $\mathrm{El},(\beta=.20, \dagger=2.20, \mathrm{P}<.05)$ and a positive interaction between forcing strategy and trait El $(\beta=.12, \dagger=1.96, P<.05)$. However, interactions between each of confronting, smoothing, compromising strategy and trait El were not significant. As shown in Fig. 1 and 2, withdrawing and forcing resolution strategies had positively associated with OCB when workers had higher trait El.

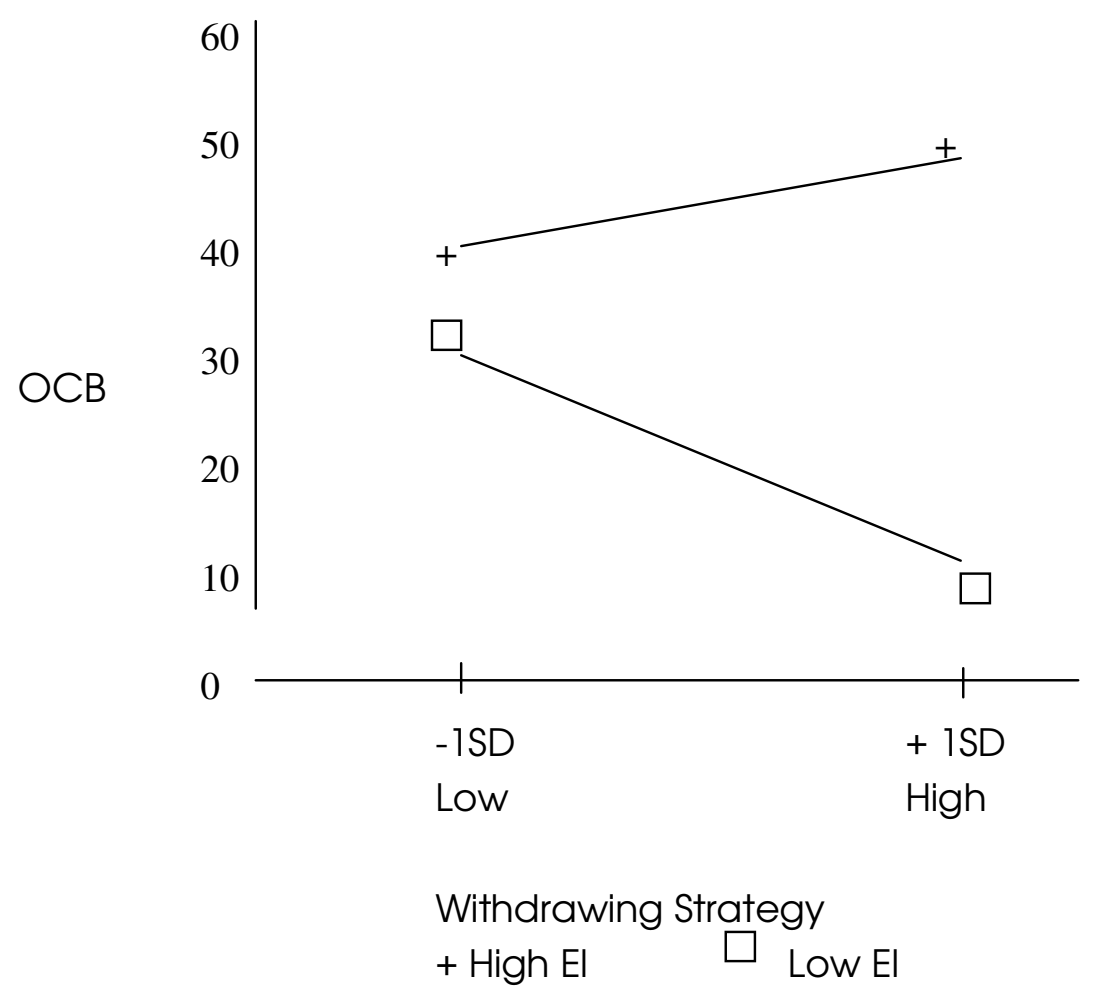

Figure 1: Interaction between Withdrawing strategy and El for $\mathrm{OCB}$ 


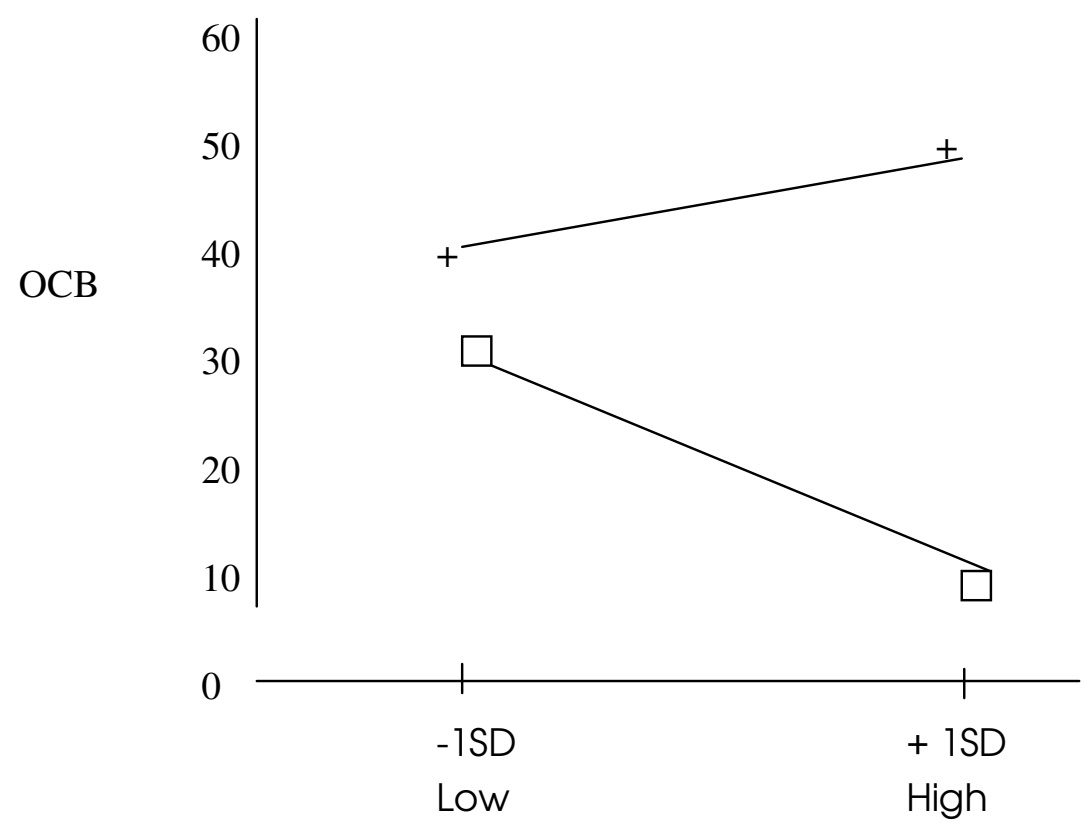

Forcing Strategy

+ High El $\square$ Low El

Figure 2: Interaction between Forcing strategy and El for OCB

However, forcing and withdrawing resolution strategies were negatively associated with OCB when the workers had low trait El. Therefore hypothesis 7 was accepted.

\section{Discussion}

This study examined how much of OCB could be predicted by conflict resolution strategies and the moderating role of trait El in the prediction.

That forcing and withdrawing strategy negatively predicted OCB show that the more the superiors used these two strategies, the less their subordinates developed OCBs. These results are in agreement with the work of Alper et al (2000), Meyer (2004), Alotaibi (2001) and Ogungbamila (2006). Explanation for these findings is that subordinates in this study felt that they have been robbed of the opportunity to share and exchange information on an issue in conflict, they felt unfairly treated and in exchange they did not develop high OCB. Instead they felt aggrieved, frustrated and developed negative attitudes toward their work and organisation resulting in lower OCB.

The findings from this study indicate that confronting, compromising, and smoothing strategies significantly predicted OCB. These results are in consonance with previous 
studies (Alotaibi, 2001; Alper et al. 2000; Giap, Hackermeier, Jiao \& Wagdarikar, 2005; Meyer, 2004; Montoro-Rodriguez \& Small, 2006; Omoluabi, 2001). An explanation of these results could be that some subordinates in this study felt that they had the opportunity to share and exchange information on the issue in conflict through their union leaders during conflict resolution with their management and they were able to negotiate adequately. This might have assisted them in developing high level of OCB.

The results indicate that subordinates with high trait El developed more OCBs. Subordinates who work with the superiors need to possess the necessary trait El in order to cope with conflict resolution strategies being adopted by their superiors and develop more OCB (Abraham, 1999; Carmeli, 2003). Employees with high trait El were able to comprehend their superiors and co-workers' feelings and were able to shift from negative to positive moods by adopting the right coping strategies to deal with stress caused by unfair treatment by superiors. Consequently they were able to develop more OCBs.

The results indicate that the interaction between $\mathrm{El}$ and forcing resolution strategy significantly predicted OCB. When forcing resolution strategy was used among subordinates who had high trait El, they were able to appraise their resources and the situation and select adaptive coping strategies to face the challenges of unfair treatment from their superiors. Mikolajczak et al. (2007) were of the view that appraisal of the situation and of one's resources are important in shaping of the subsequent emotional response and that self-efficacy and challenge/threat appraisals could be used to explain the moderating role of trait El on stress reactivity. Consequently, they developed more OCBs. For subordinates who had lower trait El, under a supervisor who used forcing resolution strategy, the reverse was the case. Their OCB reduced significantly.

The results showed that the interaction between trait El and withdrawing resolution strategy significantly predicted OCB. An explanation for this result was that subordinates who had high trait El under superiors who used withdrawing resolution strategy would be able to select adaptive coping strategies to seek for fair treatment from their employers. Consequently, subordinates with high trait El would be able to enact more OCBs (Mikolajczak, Petrides, Luminet \& Coumans, 2007). Under similar superiors who used withdrawing resolution strategy, subordinates with lower trait El would be unable to select adaptive coping strategies in dealing with the negative events (Mikolajczak et al., 2008; Mikolajczak, Luminet, Fillee \& de Timary, 2007). Hence, their OCBs would significantly decrease. These results are 
consistent with research findings that trait $\mathrm{El}$ is a moderator of the relationship between conflict resolution strategies and OCBs (Carmeli, 2003; Martins, Eddleston \& Veiga, 2002). The interaction between each of confronting, smoothing, compromising strategies and trait El were not significant in predicting OCB. This is because each of these conflict resolution strategies has a more win/win orientation, include cooperativeness and less assertiveness dimensions. These conflict resolution strategies could predict OCB regardless of the level of El of the employees. By and large, findings from this study showed that conflict resolution strategies and trait $\mathrm{El}$ predicted OCB. Furthermore, trait El moderated the relationship between forcing and withdrawing conflict resolution strategies and OCB.

The present findings have both theoretical and practical implications. Previous studies that examined factors affecting work attitudes and behaviours of workers have highlighted the need for superiors/managers to be seen to be just and fair to their subordinates during conflict resolution. Although, if the management itself is a party in the conflict, during the conflict some natural processes can occur that make us view the opponent in a negative light. The findings from this study have built on this by demonstrating the importance of trait El in the resolution of conflicts in organisations in order to elicit the most positive reactions from workers after resolving workplace conflicts and to enhance OCB among them.

An important theoretical implication of the findings from this study regarding the efficacy of conflict resolution strategies and trait El in predicting OCB is that Organisational/Industrial Psychologists should include conflict resolution strategies and trait El in a model design to enhance the OCB of workers in organisations.

Given that conflict resolution strategies and trait El have been implicated in this study in enhancing OCB of workers, practical steps should be taken to train supervisors to adopt the conflict resolution strategies that can ensure information exchange and sharing on issues of conflict in the workplace. Another practical implication of the findings from this study is that supervisors should be cautioned on the use of forcing and withdrawal strategies when resolving conflicts with subordinates. Similarly union leaders should avoid the use of forcing and withdrawal strategies with resolving conflicts with their organisational management. Furthermore, because trait El predicted $\mathrm{OCB}$ and moderated the relationship between conflict resolution strategies and $\mathrm{OCB}$, efforts should be made to enhance the trait $\mathrm{El}$ of the workers through trait El education and training by counselling/organisational psychologists. 
This study is not without its limitations, one of which is the self-report measures used in data collection. Future studies could, therefore, complement these measurements with other methods such as interview and focus group discussion techniques. Another shortcoming is the cross-sectional nature of the study and as such a longitudinal study that would span over one or two years is suggested in future research so that cause-and-effect relationships could be established. Lastly, this study used a heterogenous group comprising employees of low, middle, and high ranks (with more in the lower ranks) in the public service. This is a limitation. Future studies could involve employees of either low, middle, or high ranks to constitute a more homogeneous sample. In conclusion, this study has demonstrated that conflict resolution strategies predicted $\mathrm{OCB}$ and that trait El moderated the relationship between the conflict resolution strategies and OCB.

\section{References}

Abraham, R. (1999). Trait El in organisations: A conceptualization. Genetic, Social and General Psychology Monographs. 125(2), 209-224.

Adebayo, D.O. (2006). The moderating effect of self-efficacy on job insecurity and organisational commitment among Nigerian public servants. Journal of Psychology in Africa. 16(1), 35-43.

Aiken, L. \& West, S. (1991). Multiple regression: Testing and Interpreting interactions, Newbury Park, CA: Sage.

Albert, I.O. (2006). Conflict management and resolution in research supervision. Paper presented at the workshop on student supervision organized by The Postgraduate School, University of Ibadan Conference Centre, University of Ibadan. March 15-16, 2005.

Allen, T.D. (2006). Rewarding good citizens: The relationship between citizenship behaviour, gender and organisational rewards. Journal of Applied Social Psychology, $36(1), 120-143$.

Alotaibi, A.G. (2001) Antecedents of organisational citizenship behaviour: A study of public personnel in Kuwait. Public Personnel Management, Fall 2001.

Alper, S., Law, K.S. \& Tjosvold, D. (2000). Conflict management efficacy, and performance on organisational teams. Retrieved on 25-8-2006 from http://www.questia.com/PM.qst?a=refresh\&docld=50010935\&type=journal. 
Carmeli, A. (2003). The relationship between trait El and work attitudes, behaviour and outcomes. Journal of Managerial Psychology, 18(8), 788-813.

Davies, M, Stankov, L. \& Roberts, R. D. (1998). Trait El: In search of an elusive construct. Journal of Personality and Social Psychology, 39 (2), 103 - 118.

Decktop, J.R., Mangel, R. \& Cirka,C.C.(1999). Getting more than you pay for: Organisational Citizenship Behaviour and pay-for-performance plans. Academy of Management Journal 42, 420-428.

Deutsch, M. (1990). Sixty years of conflict. The International Journal of Conflict Management. 1, 237-263.

Dzurgba, A. (2006). Prevention and management of conflict. Ibadan: Loud Books (Publishers).

Furnham, A., \& Petrides, K.. (2003). Trait emotional intelligence and happiness. Social Behaviour and Personality; 31 (8), 815 - 824.

Garma, R., Bove, L.L. \& Bratton, V.K. (2008). Customer organisational citizenship behaviour: A coping mechanism in the stressor-strain psychological job outcomes model. Retrieved on March 8, 2008 from www.sobmedia.commerce.otago.ac.ns/aspmaco?/anzmac.

Geher, G., Warner, R.M. \& Brown, A.S. (2001). Predictive validity of the emotional accuracy research scale. Intelligence, 29 (5), 373 - 388.

Giap, B.N., Hackermeier, I., Jiao, X. \& Wagdarikar, S.P. (2005). Organisational citizenship behaviour and perception of organisational justice in students jobs. Psychology of Excellence, Instructional Design, Job Analysis and Job Design. Ludwig Maximillans University, Munich. Retrieved March 22, 2008 from http://www.reinhausenoffice.de/excellence-solutions/Research OCB.pdf.

Hoffman, B.J, Blair,C.A, Meriac, J.P, Woehr, D.J. (2007). Expanding the criterion domain? A quantitative review of the OCB literature. Journal of Applied Psychology, 92(2), 555566.

Howart, G. \& London, M. (1980). Attributions of conflict management strategies in superior subordinate dyads. Journal of Applied Psychology, 65, 172-175. 
LePine, J.A, Erez, A, \& Johnson, D.E, (2002). The nature and dimensionality of organisational citizenship behaviour: A critical review and meta-analysis. Journal of Applied Psychology, 87,52-65.

Martins, L.L; Eddleston, K.A. \& Veiga, J.E. (2002) Moderators of the relationship between work-family conflict and career satisfaction. Academy of Management Journal, 45 (2), $399-409$.

Mayer, J.P. \& Salovey, P. (1997). "What is trait El? Implications for educators", in Salovey, P. and Sluyter, D. (Eds.), Emotional Development, Emotional Literacy, and Trait El: Educational Implications (pp. 31-34). New York: Basic Books.

McShane, S.L. \& von Glinow, M.A. (2000). Organisational behaviour. (pp. 412-416). Boston: McGraw Hill.

Mikolajczak, M., Nelis, D., Hansenne, M. \& Quoidbach, J. (2008). If you can regulate sadness, you can probably regulate shame: Association between trait emotional intelligence, emotion regulation and coping efficiency across discrete emotions. Personality and Individual Differences, 44, 1356 - 1368.

Mikolajczak, M., Petrides, K.V., Luminet, O. \& Coumans, N. (2007). An experimental investigation of the moderating effect of trait emotional intelligence on laboratoryinduced stress. Submitted fro publication.

Mikolajczak, M. Roy, E. Luminet, O., Fillee, C. \& de Timary, P. (2007). The moderating impact of emotional intelligence on free cortisol responses to stress. Pyschoneuroendocrinology, 32, 1000 - 1012.

Mikolajczak, M., Luminet, O., Leroy, C. \& Roy, E. (2007). Psychometric properties of the trait emotional intelligence questionnaire: Factor structure, reliability, construct and incremental validity in a French Speaking population. Journal of Personality Assessment, $88,338-353$.

Mikolajczak, M., Menil, C. \& Luminet, O. (2007). Explaining the protective effect of trait emotional intelligence regarding occupational stress. Exploration of emotional labour process. Journal of Research in Personality. 14, 1107 - 1117.

Miles, D.E., Borman, W.E., Spector, P.E. \& Fox, S. (2002). Building an integrated model of extra role work behaviour: A comparison of counterproductive work behaviour with organisational citizenship behaviour. International Journal of Selection and Assessment, $10,51-57$. 
Montoro-Rodriguez, J. \& Small, J.A. (2006). The role of conflict resolution styles on nursing staff morale, burnout and job satisfaction in long-term care. Journal of Aging and Health. 18(3), 385-406.

Moorman, R. (1991). Relationship between organisational justice and organisational citizenship behaviours: Do fairness, perceptions influence employee citizenship? Journal of Applied Psychology. 76, 845-855.

Ogungbamila, B. (2006). Relational conflict resolution strategies (RCRS) and workplace frustration. Journal of Psychology in Africa, 16(1), 59-64.

Omoluabi, P.F. (2001). Principles of processes of conflictology. Ife Psychologia, 9(3), 1-13. Organ, D.W. (1988). Organisational citizenship behaviour: The good soldier syndrome, Lexington, MA: Lexington Books.

Pearson, C.M., Anderson, L.M. \& Porath, C.C. (2000). Assessing and attacking workplace civility. Organisational Dynamics, 29(2), 123-137.

Petrides, K.V., Perez-Gonzalez, J.C. \& Furnham, A. (2007). On the criterion and incremental validity of trait emotional intelligence. Cognition \& Emotion, 21, 26 - 55.

Petrides, K.V. \& Furnham, A. (2003). Trait emotional intelligence: Behavioural validation in two studies of emotion recognition and reactivity to mood induction. European Journal of Personality, 17, $39-57$.

Petrides, K.V. \& Furnham, A. (2001). Trait emotional intelligence: Psychometric investigation with reference to established trait taxonomies. European Journal of Personality, 15, $425-448$.

Podsakoff, P.M. \& MacKenzie, S.B. (1994). Organisational citizenship behaviour and sales unit effectiveness. Journal of Marketing Research, 31, 351-363.

Podsakoff, P.M., Ahearne, M. \& Mackenzie, S.B. (1997). Organisational citizenship behaviour and the quantity and quality of work group performance. Journal of Applied Psychology, 82(2), 262-270.

Podsakoff, P.M., Mackenzie,S., Pain, B, \& Bachrach,D.(2000).organisational citizenship behaviour: A critical review of the theoretical and empirical literature and suggestions for future research. Journal of I Management, 26(3), 513-563. 
Prati, L.M. (2004). Trait El as a facilitator of the emotional process. Ph.D. Thesis Department of Management. The Florida State University of college of Business.

Salami, S.O. (2007). Moderating effect of trait El on the relationship between emotional labour and organisational citizenship behaviour. European Journal of Social Sciences 5(2), 142-150.

Salami, S.O. (2008). Impact of job satisfaction and organisational commitment on organisational citizenship behaviour: The moderating role of group cohesiveness. Perspectivse in Education, 24(1), 41-50.

Sverke, M., Hellgren, J. \& Naswell, K. (2006). Job insecurity: A literature review. Retrieved on March 7, 2006 from http://ebib.arbetslivsinstitutet.se/saltsa/2006_01.pdf.

Wong, C.S. \& Law, K.S. (2002). The effects of leader and follower trait El on performance and attitudes. An exploratory study. The Leadership Quarterly, 13, 243-274.

Williams,L.J, \& Anderson,S.E, (1991). Job satisfactory and organisational commitment as predictors of organisational citizenship and in-role behaviours. Journal of Management, $17,601-617$.

Zellars, K.L., Tepper, B.J. \& Duffy, M.K. (2002). Abusive supervision and subordinates' organisational citizenship behaviour. Journal of Applied Psychology, 87(6), 1068-1076.

About the author:

DR S.O Salami is a Doctor of philosophy in counseling psychology. He is currently a senior lecturer at the department of Guidance and Counseling, University of Ibadan, Ibadan, Nigeria. He has published several articles in local and international journals. His areas of research interest include application of emotional intelligence and selfefficiency, mentoring, career development, psychological well-being, organisational citizenship behaviour, organisational commitment and conflict resolution.

E-mail: drsosalami2002@yahoo.co.uk 